\title{
Vínculos empregatícios, condições de trabalho e saúde entre motoristas de caminhão
}

\author{
Employment contract, work and health conditions among truck drivers \\ Vínculos laborales, condiciones de trabajo y salud de conductores de
} camión

\author{
Luna Gonçalves da SILVA ${ }^{1, a}$ \\ Andréa Aparecida da LUZ ${ }^{a}$ \\ Suleima Pedroza VASCONCELOS ${ }^{b}$ \\ Elaine Cristina MARQUEZE \\ Claudia Roberta de Castro MORENO \\ Universidade de São Paulo, São Paulo, Faculdade de Saúde Pública, Departamento de Saúde Ambiental, SP, Brasil ${ }^{a}$, \\ Universidade Federal do Acre, Rio Branco, AC, Brasil ${ }^{\mathrm{b}}$, Universidade Católica de Santos, Santos, SP, Brasil
}

Motoristas de caminhão estão sujeitos a condições de trabalho que podem contribuir significativamente para o comprometimento de sua saúde. O objetivo deste estudo foi analisar discursos de motoristas de caminhão sobre condições de trabalho e saúde, mediante as modalidades de vínculos empregatícios. A pesquisa qualitativa utilizou o método da Análise Coletiva do Trabalho e contou com a participação de 40 motoristas de caminhão, autônomos $(n=20)$ e contratados $(n=20)$, de uma transportadora do Estado de São Paulo. Foram realizadas quatro entrevistas em grupo, nas quais os trabalhadores de cada vínculo descreveram sua atividade, partindo da pergunta norteadora "O que você faz no trabalho?". Os discursos, gravados e transcritos, foram analisados por meio da Análise de Conteúdo de Bardin, sendo elaboradas duas categorias: Condições de trabalho e Saúde. Os motoristas autônomos dependiam do número de cargas transportadas comissionadas e reportaram maior liberdade e autonomia na escolha dos destinos e rotas, além da possibilidade de levar familiares nas viagens. Tanto os motoristas contratados quanto os autônomos mencionaram a precariedade na infraestrutura das rodovias brasileiras e dos postos de parada. A precarização no trabalho e os curtos prazos de entrega foram relacionados ao consumo de drogas, como anfetaminas, cocaína e crack. A informalidade e a precarização presentes nessa profissão, configuradas pela terceirização, comprometem as condições de trabalho e saúde dos trabalhadores submetidos ao mesmo contexto.

Palavras-chave:

Condições de trabalho; vínculos empregatícios; saúde.

Abstract Truck drivers' working conditions can contribute significantly to impairing their health. This study examined truck drivers'statements regarding working conditions and health, by type of employment relationship. The qualitative research used the Collective Analysis of Work method with the participation of 40 truck drivers, some self-employed $(n=20)$ and others working under contract $(n=20)$, with a transport firm in São Paulo State, Brazil. In four group interviews, grouping by employment relationship type, the workers described their activity in response to the guiding question "What do you do at work?". Once recorded and transcribed, the statements were subjected to Bardin Content Analysis, from which two categories were developed: "Working conditions" and "Health". The self-employed drivers depended on the number of loads commissioned and transported, and reported greater freedom and autonomy in choosing destinations and routes, in addition to being able to take family members along on their trips. Both contractors and self-employed drivers mentioned the deficient state of Brazil's highway and truck-stop infrastructure. Precarious labor relations and short delivery timeframes were related to use of drugs including amphetamines, cocaine, and crack. Informal and precarious employment

\footnotetext{
Endereço para correspondência: Faculdade de Saúde Pública da USP, Depto. de Saúde Ambiental, Avenida Doutor Arnaldo, n 715 , Cerqueira César, Sao Paulo, SP, Brasil 01246-904. Email: crmoreno@ usp.br. Apoio Financeiro: Conselho Nacional de Desenvolvimento Científico e Tecnológico (CNPq), número do processo 132661/2009-8. Agradecimentos: À transportadora estudada, por abrir suas portas e todos os motoristas de caminhão que contribuíram para esta pesquisa.
} 
relations, typically involving sub-contracting, jeopardized the working and health conditions of these and other workers in the same context.

Keywords:

Working conditions; employment relations; health.

\section{Resumen}

Conductores de camión se someten a condiciones de trabajo que pueden contribuir significativamente al comprometimiento de su salud. El objetivo de este estudio es analizar discursos de conductores de camión acerca de condiciones de trabajo y salud, mediante las modalidades de vínculos laborales. Este estudio, de carácter cualitativo, utilizó el método de Análisis de Compilación del Trabajo y contó con la participación de 40 conductores de camión, autónomos $(n=20)$ y contratados $(n=20)$, de una transportadora del Estado de São Paulo (Brasil). Se realizaron cuatro entrevistas en grupo, en las que los trabajadores de cada vínculo describieron su actividad, partiendo de la siguiente pregunta: ¿Qué haces en tu trabajo? Los discursos fueron grabados y transcriptos y, luego, analizados por medio del Análisis de Contenido de Bardin. Se elaboraron dos categorías: Condiciones de trabajo y salud. Los conductores autónomos dependían del número de cargas comisionadas y transportadas, y reportaron mayor libertad y autonomía para elegir los destinos y rutas, además de la posibilidad de llevar familiares en los viajes que realizan. Tanto los motoristas contratados como los autónomos mencionaron la precariedad de la infraestructura de las carreteras brasileñas y de las estaciones de parada. La precariedad en el trabajo y los cortos plazos de entrega fueron relacionados con el consumo de drogas como anfetaminas, cocaína y crack. La informalidad y la precarización presentes en esta profesión, constituidas por la subcontratación, comprometen las condiciones de trabajo y salud de los trabajadores sometidos al mismo contexto. Palabras-clave:

Condiciones de trabajo; vínculo laborales; salud.

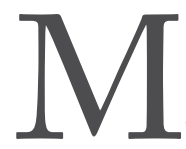

otoristas de caminhão, quando atuantes em empresas, podem exercer sua atividade tanto como empregados, ou relacionados a algum tipo de chefia, quanto como autônomos com seu próprio veículo (Kapron, 2012). Dependendo da empresa transportadora, considera-se motorista autônomo o trabalhador agregado e o terceirizado. Em alguns casos, o motorista agregado é considerado um trabalhador terceirizado. Apesar das diferentes denominações, o motorista agregado geralmente caracteriza-se por ter parte do veículo, o qual agrega na empresa, e o motorista terceirizado por ter o veículo, prestando serviço na empresa (Silva, 2011).

De acordo com os dados da Agência Nacional de Transportes Terrestres, o Transporte Rodoviário de Cargas (TRC) tem uma presença expressiva de motoristas autônomos no mercado de trabalho brasileiro, representando 83\%, e uma menor proporção de trabalhadores contratados por empresas transportadoras (16\%) e por cooperativas (1\%) (ANTT, 2014). Nesse contexto, analisar os vínculos empregatícios para compreender os modos de trabalhar dos motoristas de caminhão torna-se fundamental, pois permite observar as relações de trabalho, as quais, marcadas pela terceirização e flexibilização no mercado de trabalho, podem provocar impactos importantes na vida e na saúde desses trabalhadores. As novas relações salariais se expressam em forma de organização laboral de caráter flexível, contratual e ocasional. Essa modalidade de produção gera, por sua vez, uma subjetividade com características como o individualismo, a ilusão de liberdade e de autorresponsabilidade (Sauaya, 2003).

Longas jornadas de trabalho, ausência de pausas para descanso, má alimentação, risco de assaltos e acidentes de trabalho prejudicam a saúde dos trabalhadores (Botelho, Diesel, Adamczyk, \& Zeferino, 2011; Codarin, Moulatlet, Nehme, Ulhôa, \& Moreno, 2010; Kapron, 2012; Martins, 2013; Rosa, 2006). Além disso, os curtos prazos de entrega não apenas dificultam a realização de pausas de descanso, como empurram muitos trabalhadores para o consumo de substâncias químicas, como anfetaminas e álcool, uma vez que precisam se manter acordados para atender as urgências dos prazos delimitados pelas empresas (Knauth, Leal, Pilecco, Seffner, \& Teixeira, 2012; Nascimento, Nascimento, \& Silva, 2007; Souza, Paiva, \& Reimão, 2005).

Além do uso de substâncias psicoativas, outras repercussões das condições de trabalho na saúde de motoristas de caminhão são apresentadas em diversos estudos. Entre os problemas e agravos à saúde mais frequentes, pode-se destacar sobrepeso e obesidade, diabetes, hipertensão, hipercolesterolemia, alterações posturais, privação e distúrbios do sono, sonolência excessiva e estresse (Ferreira \& Alvarez, 2013; Leyton et al., 2012; Oliveira et al., 2015; Penteado, Gonçalves, Costa, \& Marques, 2008; Pylkkönen et al., 2015; Ulhôa et al., 
2010).O estudo de Cerqueira-Santos e Santana (2014), ao analisar a percepção da satisfação com o trabalho de 342 motoristas de caminhão, autônomos e empregados, de diversos estados do Brasil, demonstrou que os motoristas que tinham vínculo empregatício indicaram maior satisfação com a empresa quando comparados aos autônomos.

Apesar das pesquisas realizadas com motoristas de caminhão (Leyton et al., 2012; Masson \& Monteiro, 2010; Moreno \& Rotenberg, 2009; Nascimento et al., 2007; Rosa, 2006; Ulhôa et al., 2010), poucas apontam e/ou investigam os vínculos empregatícios como um elemento importante das condições de trabalho nas quais os profissionais estão submetidos (Cerqueira-Santos \& Santana, 2014; Kapron, 2012). Tais condições, por sua vez, podem produzir rotinas e relações de trabalho diferentes entre os profissionais, bem como possíveis consequências distintas na saúde dos trabalhadores.

Recentemente, os motoristas de caminhão obtiveram conquistas históricas enquanto categoria, bem como passaram por intensas mudanças legais. A fim de regular e disciplinar a jornada de trabalho, bem como diminuir os acidentes envolvendo os profissionais nas rodovias brasileiras, em 2012, a Lei 12.619/2012 regulamentou a profissão, a jornada de trabalho e o tempo de direção de motoristas profissionais. Entretanto, seus dispositivos foram revogados e, impulsionada pela importante mobilização nacional de motoristas de caminhão, em fevereiro de 2015, essa lei sofreu alterações quanto à regulamentação da jornada de trabalho e do tempo de descanso. As mudanças incluíram o aumento da jornada de trabalho para até 12 horas, com tempo máximo ao volante para até $5 \mathrm{~h}$ e meia, bem como a diminuição do tempo de descanso semanal remunerado do motorista empregado de 35h para 24h. Em março de 2015, a Lei dos Caminhoneiros (Lei 13.103/2015) foi sancionada e está em vigor.

Com base no que foi exposto, identifica-se, portanto, a necessidade de incluir os vínculos empregatícios na compreensão do trabalho de motoristas de caminhão, bem como considerá-los um aspecto significativo na discussão sobre os impactos dessa atividade para a saúde dos profissionais. Dessa forma, este estudo teve como objetivo analisar os discursos de motoristas de caminhão sobre condições de trabalho e saúde, mediante as modalidades de vínculos empregatícios desses trabalhadores.

\section{MÉTODO}

\section{Tipo de estudo}

Trata-se de um estudo aportado na metodologia qualitativa, considerando os conteúdos subjetivos e o universo de significados, vivências e valores oriundos dos relatos dos participantes (Strauss \& Corbin, 2008).

\section{Local de estudo}

A coleta de dados ocorreu no período de junho a agosto de 2010 em uma transportadora de cargas do Estado de São Paulo. Na época da coleta, a empresa pesquisada existia há mais de 25 anos, era considerada uma das líderes de mercado no transporte rodoviário de cargas e possuía 40 unidades em 19 estados do Brasil. Quanto aos tipos de carga, transportava diferentes mercadorias, incluindo produtos a granel, ensacados, ferro, açúcar, papel, químicos e petroquímicos.

Nessa empresa, os motoristas contratados, ou da "frota", eram aqueles trabalhadores contratados formalmente pela empresa e com veículo da própria transportadora. Os motoristas autônomos se dividiam em dois grupos: agregados e terceirizados. Os agregados tinham o cavalo mecânico e usavam a carreta da empresa em consignação. Esses trabalhadores assinavam um contrato de trabalho exclusivo como prestadores de serviço. Já os terceirizados, eram donos do cavalo mecânico e da carreta, e não eram prestadores de serviço exclusivos da empresa.

Todavia, durante as entrevistas, identificou-se outro tipo de vínculo de trabalho entre os motoristas, os quais denominamos "quarteirizados". Esses, também autônomos, prestavam serviços aos motoristas terceirizados que trabalhavam para a empresa estudada. Trabalhavam com o veículo do motorista terceirizado e não tinham nenhum tipo de vínculo com a transportadora.

\section{Participantes}

Foram convidados a participar voluntariamente 20 motoristas contratados formalmente pela empresa e 20 autônomos, desses, 9 agregados, 10 terceirizados e 1 quarteirizado, totalizando 40 participantes do sexo masculino. 
Todos os motoristas tinham ensino fundamental completo, $87,5 \%$ eram casados e tinham filhos. A faixa etária variou de acordo com o vínculo de trabalho, motoristas contratados e terceirizados apresentaram grande semelhança, com idades entre 35 e 65 anos $(M=36,5$ anos; $D P=11,5)$ e os agregados entre 20 e 30 anos $(M=25$ anos; $D P=7,1)$. A renda mensal dos motoristas entrevistados era muito variável e dependia da comissão. $\mathrm{O}$ trajeto realizado por eles contemplava as regiões Sul, Sudeste, Nordeste e Centro-Oeste.

\section{Instrumento}

Nesta pesquisa, o instrumento utilizado foi a entrevista em grupos, tendo como pergunta norteadora "O que você faz no trabalho?”. Para tanto, utilizou-se o método da Análise Coletiva do Trabalho (ACT), que, segundo Ferreira (1993), é também um conjunto de conhecimentos que analisam o trabalho. A ACT, por sua vez, tem origem na Ergonomia e pode ser definida como um conjunto de conhecimentos que objetiva a melhor adaptação das situações de trabalho aos trabalhadores (Ferreira, Maciel, \& Paraguay, 1994). Nessa perspectiva, a ACT, já utilizada em diversos trabalhos (Ferreira, 1993; Ferreira, 2011; Ferreira, Donatelli, \& Junior, 2003; Ferreira, Gonzaga, Donatelli, \& Bussacos, 2008; Ferreira \& Iguti, 1996; Mendonça, Souza, \& Ferreira, 2009), possibilita a existência de um espaço oficial, onde o trabalhador, no coletivo, fale sobre seu trabalho. A partir dessa experiência, os profissionais não apenas trazem o conhecimento que têm sobre seu trabalho e sua atividade, mas podem ampliar sua capacidade de análise sobre seu próprio fazer (Ferreira et al., 2003; Ferreira \& Iguti, 1996).

Trata-se de encontros nos quais se reúne um grupo de trabalhadores, voluntários, que descrevem aos pesquisadores a sua atividade, a partir de uma pergunta condutora, a qual deve ser respondida ao máximo. As reuniões devem ser realizadas sem a presença de chefia, resguardando o anonimato dos trabalhadores, sendo conduzidas por, ao menos, dois pesquisadores (Ferreira, 1993; Ferreira, 2011; Ferreira et al., 2003; Ferreira \& Iguti, 1996; Mendonça et al., 2009).

\section{Procedimentos da coleta de dados e cuidados éticos}

Neste estudo, foram realizados quatro encontros com os motoristas de caminhão de diferentes vínculos de trabalho na sede da própria transportadora, devido à dificuldade em encontrar os participantes fora do local de trabalho, além da irregularidade dos seus horários de trabalho. $\mathrm{Na}$ medida em que os encontros de ACT ocorreram dentro da empresa estudada, foi acordada a disposição de um local privativo para a realização das entrevistas com os grupos, a liberação dos motoristas no período da coleta, bem como a autorização para a publicação dos resultados encontrados, resguardando o anonimato da transportadora e dos participantes da pesquisa. Quanto aos cuidados e preceitos éticos em pesquisa, este trabalho foi aprovado pelo Comitê de Ética da Faculdade de Saúde Pública da Universidade de São Paulo, sob protocolo n 2050, conforme Resolução no 196/96 do Conselho Nacional de Saúde.

Quanto aos grupos de ACT e o número de participantes, foi realizado um encontro com motoristas contratados $(n=10)$, um com motoristas agregados $(n=6)$, um com motoristas terceirizados $(n=9)$ e um grupo misto com trabalhadores de cada vínculo (contratados, agregados, terceirizados e quarteirizado, respectivamente $n=10, n=3, n=1$ e $n=1$ ), no qual foi possível validar os dados encontrados nos grupos anteriores, conforme recomendações (Ferreira \& Iguti, 1996; Mendonça et al., 2009).

\section{Procedimentos de análise dos dados}

Mediante o consentimento dos motoristas e a assinatura do Termo de Consentimento Livre e Esclarecido (TCLE) para participar da pesquisa, os encontros foram gravados e o conteúdo foi transcrito integralmente, garantindo a fidelidade dos relatos dos participantes. As análises deste material foram realizadas utilizando-se o referencial da análise temática segundo a Análise de Conteúdo proposta por Bardin (Bardin, 2009).

Dessa forma, a organização e a análise dos dados foram realizadas de acordo com as seguintes etapas: leitura do material, seleção do material empírico a ser analisado seguindo os requisitos da análise temática - exaustividade, representatividade, homogeneidade e pertinência -, e, por fim, a escolha das categorias analíticas mediante os objetivos deste estudo. 


\section{RESULTADOS}

Os resultados foram organizados de acordo com as categorias e subcategorias emergentes das análises dos discursos dos participantes mediante o tipo de vínculo empregatício. A categoria Condições de trabalho apresentou as seguintes subcategorias: A atividade; A infraestrutura: o caminhão, os postos de parada e as estradas brasileiras; O sistema de rastreamento: uma medida de segurança?; Os prazos de entrega e Composição salarial. Para a categoria Saúde, foi elaborada a subcategoria Se você estiver com sono e precisar rodar. Os tipos de vínculo de trabalho e suas características podem ser mais bem compreendidos na Tabela 1.

TABELA 1. Características dos vínculos de trabalho, segundo presença ou não de contrato de trabalho com a empresa estudada, salário fixo, comissão, caminhão e possibilidade de escolher rotas na transportadora.

\begin{tabular}{cccccc}
\hline Vínculo empregatício & Contrato & Salário fixo & Comissão & Caminhão próprio & Escolha das rotas \\
Contratado & Sim & Sim & Sim & Não & Não \\
Agregado & Sim & Não (Frete) & Sim & Sim ${ }^{\star *}$ & Não \\
Terceirizado & Não & Não (Frete) & Sim & Sim/Não & Sim \\
Quarteirizado & Não & Não (Frete) & Sim $^{*}$ & Não & Não
\end{tabular}

Nota. * A renda final do motorista quarteirizado era referente a 10 a $13 \%$ da renda final do motorista terceirizado, depois de descontadas todas as despesas com o veículo.** Agrega-se parte do veículo, no caso, o cavalo mecânico.

Quando questionados sobre os aspectos positivos e negativos de cada vínculo empregatício, os motoristas de caminhão apontaram outro vínculo, que não o seu, como o mais vantajoso, conforme demonstrado na Tabela 2 .

TABELA 2. Aspectos positivos e/ou possíveis vantagens de cada vínculo, segundo os motoristas de caminhão.

\begin{tabular}{|c|c|}
\hline $\begin{array}{l}\text { Vínculo } \\
\text { empregatício }\end{array}$ & Aspectos positivos/vantagens \\
\hline Contratado & $\begin{array}{l}\text { Salário fixo e pagamento de diárias; não viajar à noite e ausência de competição entre os motoristas para a } \\
\text { melhor carga (melhor frete). }\end{array}$ \\
\hline Agregado & $\begin{array}{l}\text { Maior remuneração; possuir o veículo/parte dele; entregar as melhores cargas; liberdade e autonomia no tra- } \\
\text { balho para escolher as rotas e decidir quando trabalhar; possibilidade de levar família na viagem; perspectiva } \\
\text { financeira futura com aquisição do veículo. }\end{array}$ \\
\hline Terceirizado & Liberdade de escolha da rota de viagem; possuir o veículo; levar a família nas viagens. \\
\hline Quarteirizado & Não houve vantagem relatada. \\
\hline
\end{tabular}

Mediante análise das entrevistas, duas categorias foram elaboradas (a) Condições de trabalho e (b) Saúde e subcategorias relacionadas, apresentadas a seguir.

\section{Categoria 1: Condições de trabalho}

Subcategoria 1. A atividade.

Falar sobre o trabalho, segundo a maioria dos participantes (independentemente do vínculo empregatício), implicava falar sobre seus sentimentos relacionados ao trabalho, notadamente, recorrendo às palavras "estressante" e "preocupação", como se observa nos relatos dos motoristas a seguir: "Estressante é quando você começa a viajar!”.

Primeiro você saiu daqui e pegou a estrada... Aqui é uma coisa, na estrada é outra. É um mundo totalmente diferente desse do que a gente vê aqui na empresa. Entendeu?! Ai vêm os perigos, vêm os irresponsáveis, vêm as pessoas boas também para te dar uma dica, entendeu?! (Motorista contratado)

A nossa preocupação quando chega aqui, é isso mesmo, de ver o que tem para carregar, o que tem para arrumar, se tá liberado [o caminhão]. São coisas que passa o dia inteiro e você não resolve nada. Aí, quando chega à noite, que épara gente rodar, a gente não roda, ai já atrasa. Eles [empresa estudada] já colocam o dia a partir de hoje [para rodar] correndo, entendeu? Dai, a gente fica com o tempo curto! (Motorista agregado) 
Nós começamos a trabalhar, assim, o dia que você sai de casa. Ai, monta no caminhão e vai. Dez dias, quinze dias, até você retornar e passar em casa. A gente chega de noite e sai de manhã, então fica difícil, não é? De repente, você tá acumulado aquilo, nervoso, muito trabalho e horário. Você tá preocupado que você tem que chegar e não vai dar. (Motorista terceirizado)

Os participantes relataram distintas preocupações sobre as condições de trabalho, de acordo com o vínculo empregatício. Os motoristas contratados referiram as diferenças existentes entre o trabalho dentro e fora da empresa, ou seja, diariamente se deparavam com as dificuldades e os riscos inesperados nas estradas, configurando o conflito entre o trabalho prescrito e o real. Entre os motoristas autônomos (agregados, terceirizados e quarteirizado), foram observados relatos recorrentes acerca da ansiedade e preocupação constante em relação ao cumprimento dos prazos estabelecidos pela empresa e para conseguir novas cargas/viagens, devido à renda mensal depender exclusivamente do número de cargas transportadas comissionadas.

\section{Subcategoria 2. A infraestrutura: $\mathrm{O}$ caminhão, os postos de parada e as estradas brasileiras.}

Como mencionado na subcategoria 1 , foram observados diferentes relatos e preocupações relacionados à atividade segundo o tipo de vínculo empregatício de cada participante. Entretanto, a infraestrutura dos postos de parada e das rodovias foi referida por todos os motoristas, independentemente do tipo de vínculo, como inadequadas e, em muitos trechos do território nacional, precárias. Sobre as condições do veículo, os motoristas contratados reportaram como inadequadas e insuficientes para atender as necessidades e demandas do trabalho, ressaltando aspectos como o desconforto físico (banco, volante, altura) e térmico (falta de ar-condicionado).

Alguns depoimentos a seguir refletem as condições dos postos de parada, segundo a percepção dos motoristas do grupo agregados.

Você come muito resto. Comida estragada. A vigilância sanitária não fiscaliza nada. Faz muita propaganda, não é? Mas, para fora, eles não fiscalizam nada não! Senão fecharia muito restaurante ai. Tem lugar que você vai usar um vaso sanitário, não tem porta. Como é que você usa? Tem lugar que não tem banheiro para tomar banho.

E a estrada, encheram de pedágio e está pior do que quando não tinha pedágio. Quer dizer, tinha que ter uma pessoa para fiscalizar isso daí. Como é que você vai pagar um pedágio caríssimo para andar numa estrada ruim? E a gente não tem para quem reclamar.

\section{Subcategoria 3. O sistema de rastreamento: Uma medida de segurança?}

Outro aspecto do trabalho relatado pelos motoristas foi o sistema de rastreamento utilizado pela empresa estudada. Segundo reportado por eles, a central de rastreamento utilizava um sistema rastreador que poderia autorizar ou não as paradas dos motoristas em postos não autorizados pela empresa. O serviço de rastreamento era feito pela própria empresa durante 24 horas ininterruptas. Estar submetido a esse sistema de segurança e rastreamento de carga era obrigatório entre os motoristas contratados e agregados, sendo opcional para os motoristas terceirizados e quarteirizado. Estes poderiam adquirir o equipamento com recursos próprios e o sistema de rastreamento variava de acordo com a empresa para a qual eles estavam prestando serviço.

Foi observado, a partir dos relatos dos participantes, que o sistema de rastreamento foi recorrente objeto de reclamações entre os motoristas contratados e agregados e não foi mencionado entre os terceirizados:

Só que o rastreador não é um bem para a gente, ele é um bem para os empresários. Esse é o tipo de bem que você é escravo, isso é uma expressão até esquisita. A escravidão é dos tempos dos negros, mas a escravidão nossa tem hoje 24 horas, você é escravo daquele aparelhinho que é uma porcaria e você é escravo 24 horas. Se eu entrar num lugar lá, precisar ir ao banheiro, ou não entrar, que quer dizer ociosidade, se eu vou ao banheiro e marcar, se passar 15, 20 minutos, ele começa a bipar lá fora. (Motorista contratado)

\section{Subcategoria 4. Os prazos de entrega.}

Foram observadas diferenças entre os vínculos empregatícios e os prazos de entrega estabelecidos pela empresa pesquisada. Os motoristas contratados mencionaram maior flexibilização dos prazos para as entregas e referiram receber um ou dois dias a mais da data prevista para realizar a entrega. Dessa forma, eles não 
precisavam "correr" para cumprir os prazos. Os motoristas terceirizados relataram que os dias concedidos para realizar as entregas eram considerados "suficientes" e o tempo de entrega era "muito sossegado".

Entretanto, os motoristas agregados referiram que o tempo para a entrega da carga começava a partir do momento em que eles chegavam à empresa para carregar o caminhão. Também mencionaram que havia uma "premiação" quando a carga era entregue no prazo contratado e determinado pela empresa.

Os motoristas autônomos (agregados, terceirizados e quarteirizado) relataram que o tempo e a experiência na profissão poderiam ser aspectos que contribuíam para a melhor administração do tempo de viagem e gerenciamento das entregas das cargas, bem como o conhecimento das melhores rotas (fretes com maior valor de comissão e caminhos mais curtos e/ou alternativos para chegar ao local de entrega).

\section{Subcategoria 5. Composição salarial.}

Os motoristas autônomos, em especial os terceirizados e o quarteirizado, mencionaram descontentamento em relação às suas condições de trabalho, como o desamparo e a insegurança salarial e de direitos trabalhistas (como folgas e serviço de assistência à saúde). De acordo com os esses motoristas, o pagamento de um salário fixo mensal contribuiria para minimizar essas dificuldades. Os motoristas autônomos revelaram sentirem-se angustiados por cumprirem, constantemente, extensas jornadas de trabalho e estarem submetidos à pressão pelo pagamento comissionado: "Eu vou falar aquilo que eu falei, é o salário, não é? Que a gente não tem, a cesta que a gente não tem, diária que a gente não tem, folga que a gente não tem”. (Motorista terceirizado)

Que é muito bagunçado, entendeu? Você não tem direito a nada! Nunca tem direito a nada! Não existe o cara só trabalhar de comissão! Não existe isso! Ele tem que ter um salário fixo e mais uma comissão! O cara tem que trabalhar 24 horas, 24 horas, 24 horas, 48 sem parar meu! Isso não existe! (Motorista agregado)

A renda do motorista contratado era calculada pela soma do salário fixo e das comissões. Para os motoristas agregados, terceirizados e quarteirizado, o valor final da renda implicava descontar do valor do frete (comissão) as despesas referentes aos custos das viagens - manutenção do veículo, alimentação, banhos, combustível e pedágios.

O pagamento do trabalhador quarteirizado dependia exclusivamente da sua produtividade e do lucro obtido pelo motorista terceirizado. Segundo esses participantes, conseguir uma viagem com um frete compensador (valor para cobrir as despesas e ainda obter lucro) era uma tarefa difícil e, ainda, conseguir um frete de retorno tornava-se uma tarefa ainda mais árdua. Para os motoristas quarteirizados, o retorno da viagem era ainda mais difícil, pois depende unicamente da obtenção de um frete de retorno pelo motorista terceirizado, o qual deveria providenciar um com valor suficiente para arcar com as despesas da própria viagem, a comissão do motorista quarteirizado e algum lucro para o motorista terceirizado (neste caso, o contratante). Nesse contexto, os motoristas quarteirizados apresentaram vínculos ainda mais frágeis e precários.

\section{Categoria 2: Saúde}

\section{Subcategoria 1. "Se você estiver com sono e precisar rodar".}

Por meio dos relatos foi possível observar recorrentes depoimentos sobre o uso de substâncias químicas e estimulantes, além do álcool e anfetaminas, como a cocaína e o crack. Segundo os participantes, a busca por essas substâncias tem se tornado uma prática constante entre os motoristas de caminhão nas rodovias e o seu uso ocorre pelo mesmo motivo do consumo de anfetaminas, ou seja, os motoristas precisam se manter acordados para atender as demandas de trabalho e os prazos de entrega exigidos pelas empresas. Sobre o consumo de álcool e anfetaminas (rebite), os motoristas narraram algumas experiências vividas nas estradas, bem como relataram alguns dos efeitos de drogas no organismo, configurando uma possível dependência dessas substâncias no trabalho.

Eu vim de carona de Fortaleza a Belo Horizonte com cegonheiro [motorista de caminhão cegonha] e eu vim com os caras e fiquei bobo! De dia, os caras andam maneirinho... $90 \mathrm{~km} / \mathrm{h}$, atrás do outro. A hora que chega a noite, é rebite, conhaque! E eles começam a rir e falam "Agora começa o terrorismo!". Rebite, redbull e conhaque. Eles fazem loucura mesmo! Os caras chegam acelerando na traseira de um carro, um carro! E chega na cola e tira! Rebite 
também, você pode dormir com o olho aberto, não é? Existem fatos aí, que você cochila porque teu olho tá aberto, você não tá com sono, você não fecha o olho, mas a tua mente dorme! (Motorista agregado)

O rebite é assim, vamos supor, você tá cansado, você não tem controle do caminhão. Parece que o caminhão puxa para direita, para esquerda, você não tem controle nenhum quando você tá com sono e cansado. Às vezes, eu tomava dois [comprimidos]. (...) Dá uma meia hora e você percebe. Talvez nem chega a meia hora, uns quinze minutos, você já percebe a droga fazendo efeito. Você tá dirigindo assim "ó", o cansaço, o sono, passa. Você fica normal, você não pisca, você fica só olhando para a estrada. Ai, você percebe que o sono quer vir e a droga vai e faz o efeito. Você percebe uma acelerada. É impressionante! Só que no outro dia, o seu estômago tá um bagaço. (Motorista terceirizado)

O grupo de motoristas autônomos reportou: "Então, o pior hoje não é o rebite. O pessoal considera muito o rebite como droga, mas essa droga que você está falando, que é a cocaina, ela hoje tá brabo!"; "É que o cansaço físico é o que mais dá acidente ou leva a pessoa pra uma droga, não é? Hoje mesmo eu estou na cocaina."; "Não sei se a senhora sabe, mas a maioria dos motoristas, não estou dizendo aqui [na empresa estudada], mas a grande parte é de drogados... a grande parte!"; "Agora, ultimamente nem rebite está tendo mais não, é carreirinha, não é? Agora o rebite não está mais fazendo muito efeito mais. Então, agora eles estão na cocaina, em tudo, em tudo o que não presta!".

Ih! O crack está empesteado, isso ai está um inferno esse tal de crack. Cada vez tem mais! Nossa! Tá virando um inferno isso ai!

Você acha que tem mais crack do que o rebite nas estradas?

Com certeza. Tem mais sabe! É barato! É muito baratinho! E os caras de um dia para o outro, eles viciam. (Motoristas contratados)

Os participantes também exemplificaram como a pasta base, o crack, auxilia os motoristas de caminhão a ficarem alertas durante o trabalho. Os motoristas agregados, por exemplo, apontaram que: "O crack (risos) te deixa renovado!"; "Vocêfica bem esperto, ligado, não é? Só que quando ela [pasta base] acaba, o efeito dela, aí vem o cansaço e o sono de uma vez, não é?".

[Pasta] Base é tipo um... ela é um pozinho que você põe ela na lata ali, faz um furinho na lata ali e fuma ela. Tira o sono, tira o cansaço. Ela dá uma aliviada no teu corpo, entendeu? Como se fosse um energético. (Motoristas agregados)

Os motoristas referiram recorrer ao consumo de drogas nessa atividade devido a necessidade do cumprimento dos prazos e de realizar um número de viagens/cargas para conseguir uma melhor remuneração: "Eu já fui usuário de droga, mas por causa de caminhão, entendeu? É pelo patrão. Têm muitas firmas ai que exigem andar. Tem cara que ganha comissão. Se ele não andar, ele não vai ganhar”. (Motorista agregado)

Tềm muitos que trabalham em cima de comissão. Você entendeu? Praticamente, eles nem têm salário. Então, quanto mais eles ganharem, o salário deles é maior. Então, eles usam "arrebite", usa droga e tudo. Roda ai três, quatro dias sem dormir. (Motorista contratado)

Eu tomei "arrebite" (sic), eu não vou mentir não. Eu precisei tomar se eu quisesse conservar o meu emprego. Eu precisava do serviço. Eu não podia sair. Eu tinha que carregar os bois e eu vi que eu não dava conta. Ai, eu tomei dois rebites com coca-cola e viajei a noite inteirinha.

Que nem, que ele [referindo-se a um colega de profissão] estava comentando que ele não toma "arrebite". Nunca tomou porque nunca trabalhou num lugar que obriga ele a fazer aquilo, entendeu? Porque se você precisa do trabalho, você depende daquilo ali, o cara te dá aquele horário para você fazer. Isso que ele falou que ele nunca precisou, é mentira. Porque lá [referindo-se à outra transportadora] o horário deles é apertado. Eles te dão lá 2.300 quilômetros 
em 48 horas. Como é que você faz? Você não pode dormir. Que nem ele falou, "dormi duas horas". Duas horas não sustentam ninguém cara, você comete o perigo do mesmo jeito. (Motoristas terceirizados)

Como alternativa para diminuir e/ou evitar o uso de drogas entre esses profissionais, bem como o possível e decorrente envolvimento em acidentes nas rodovias, os motoristas de caminhão entrevistados sugeriram, além do fim da dinâmica produtividade/comissão, a regulamentação da jornada de trabalho:

A culpa é da fiscalização que não chega junto para punir esse pessoal. Se tivesse o próprio ato do governo, que toma conta disso aí.. O sindicato, se é que ajuda em alguma coisa, era para fazer isso aí. Mas se você não chega junto com eles, nem a carteira do cara assina. Ai o que acontece? O cara vem a $200 \mathrm{~km} / \mathrm{h}, 150 \mathrm{~km}, 120 \mathrm{~km}, 200 \mathrm{~km}$. Deus me perdoe quem está vindo de lá. Só que ai vai ficar naquela bistória, quando não tem a droga, tem o rebite e quando não tem o rebite, tem a droga. Porque ele vai ter que rodar mais para chegar adiantado. (Motorista contratado)

\section{DISCUSSÃO}

Quanto aos vínculos empregatícios, os achados deste estudo mostraram que os motoristas contratados referiram renda fixa mensal, rotas preestabelecidas pela empresa, problemas com o sistema de rastreamento e prazos de entrega flexíveis. Os motoristas autônomos dependiam do número de cargas transportadas comissionadas e reportaram maior liberdade e autonomia na escolha dos destinos e rotas, além da possibilidade de levar familiares nas viagens. Relatos sobre as dificuldades (trabalho informal e precário e condições dos postos de parada e das rodovias) e a imprevisibilidade presentes no exercício da profissão foram bastante recorrentes entre os motoristas de todos os vínculos empregatícios.

O trabalho precário caracteriza-se pela imprevisibilidade na qual os empregadores isentam-se de responsabilidades e os riscos são assumidos pelos próprios trabalhadores. Além dos prejuízos causados pelo processo de precarização nos ambientes laborais, tais danos estendem-se para o mundo fora do trabalho, atingindo a sociedade e os lares de trabalhadores (Kalleberg, 2009).

A qualidade das estradas afeta diretamente as condições de trabalho dos motoristas de caminhão e a precariedade das rodovias torna a viagem ainda mais difícil e perigosa, configurando-se como um dos fatores que contribuem para o estresse dos profissionais e para a ocorrência de acidentes (Rosa, 2006; Ulhôa et al., 2010).

Sobre a infraestrutura dos postos de parada, o Ministério dos Transportes tem realizado o mapeamento dos locais de parada para o descanso dos caminhoneiros em todas as rodovias federais (Ministério dos Transportes, 2014). A iniciativa pretende reconhecer as condições gerais dos atuais estabelecimentos, selecionar pontos de parada que possam atender as mudanças na Lei dos Motoristas, aprovada em abril de 2015, cujas atribuições destacam-se a regulamentação da jornada de trabalho e o tempo de descanso dos motoristas de caminhão, bem como colher subsídios que devem sair da iniciativa privada para melhorar a infraestrutura dos postos de parada.

O sistema de rastreamento, recurso utilizado por inúmeras empresas transportadoras que buscam diminuir as chances de roubos de cargas, tem o monitoramento feito por uma equipe que permanece em salas de controle acompanhando todo o movimento do veículo via satélite (Moreno \& Rotenberg, 2009). Contudo, os depoimentos aqui apresentados revelaram que essa medida de segurança dificulta o trabalho dos profissionais, pois apresenta falhas na comunicação entre a central de atendimento e motoristas de caminhão, bem como expõe os trabalhadores a situações de risco e acidentes nas rodovias.

Rosa (2006) observou em estudo com motoristas de caminhão que ter uma renda fixa mensal foi considerado um aspecto positivo no trabalho. Este estudo corrobora esses achados, uma vez que ter uma renda fixa mensal foi reportada como uma "vantagem" dos motoristas contratados sobre os demais vínculos. O grupo de motoristas autônomos (agregados e terceirizados) relatou a "autonomia" em relação às escolhas dos trajetos e aos horários de trabalho e a possibilidade de viajar com os familiares.

Para cumprir as urgências dos prazos de entrega estabelecidos pelas empresas e suportar o cansaço físico durante a jornada de trabalho, muitos caminhoneiros recorrem ao consumo de anfetaminas, conhecidas como rebite, muitas vezes associado ao álcool (Penteado et al., 2008), pois seu efeito ajuda a evitar o sono (Nascimento et al., 2007). As anfetaminas, estimulantes do sistema nervoso central, quando usadas indiscriminadamente, 
podem provocar danos irreversíveis para a saúde, como: alucinações visuais, delírios, perda de apetite, aumento da temperatura do corpo, taquicardia, dilatação das pupilas, entre outros (Rosa, 2006).

De acordo com os motoristas entrevistados, recorrer ao uso de drogas, como cocaína e crack, vem se tornando uma prática cotidiana e uma realidade vivida por muitos profissionais nas rodovias brasileiras. Os trabalhadores afirmaram que drogas como a anfetamina e o crack têm baixo custo e são facilmente encontradas nos postos de descanso e alimentação (Leyton et al., 2012). Diversos estudos apontam o comprometimento à saúde decorrente do uso de cocaína e crack, incluindo prejuízos neuropsicológicos, psiquiátricos, pulmonares e cardiovasculares (Marques, Ribeiro, Laranjeira, \& Andrada, 2012; Scheffer, Pasa, \& Almeida, 2010). Contudo, apesar de alguns motoristas entrevistados terem consciência sobre os efeitos e repercussões do consumo de drogas, ainda recorrem a essa alternativa para se manterem acordados para trabalhar e cumprir os prazos de entrega (Knauth et al., 2012; Masson \& Monteiro, 2010; Penteado et al., 2008; Williamson, 2007).

Os resultados observados desvelam que discutir o consumo de drogas e suas repercussões para a saúde implica compreender o contexto de trabalho no qual os motoristas de caminhão estão inseridos. Ressalta-se que, para a implementação de medidas preventivas de saúde, é fundamental considerar as condições e os processos de trabalho, e não apenas focar na mudança do comportamento individual dos trabalhadores (Vilela, Iguti, \& Almeida, 2004).

Regulamentar a profissão e a jornada de trabalho representa um marco importante na história da profissão, pois, legitima e oficializa a atividade dos motoristas de caminhão, já existente há décadas. Todavia, logo após a aprovação da Lei 13.103/2015, um projeto de lei que legaliza a terceirização no Brasil está em fase de aprovação de emendas. É importante destacar que a câmara dos deputados aprovou uma emenda que permite que empresas subcontratem todos os serviços, incluindo atividades-fim e não somente atividades-meio (Projeto de Lei n. 4330/2004).

A aprovação desse projeto pode autorizar e legitimar também todos os elementos constitutivos do processo de terceirização: a precariedade no trabalho, a informalidade, a instabilidade, a insegurança, a competitividade e a falta de união entre trabalhadores, os prejuízos nos direitos trabalhistas e a impunidade de empresas que exploram e/ou não proporcionam condições dignas de trabalho aos seus colaboradores. Os impactos trabalhistas e sociais de tal aprovação podem trazer sérias repercussões para a vida e para a saúde da classe trabalhadora e da sociedade de modo geral.

A terceirização produz efeitos significativos na subjetividade dos trabalhadores, na medida em que gera insegurança nas relações trabalhistas, desconstrução da coletividade e da cidadania, bem como conduz os indivíduos à impossibilidade de planejar e ter um modo de vida mais equilibrado e estável (Barros \& Mendes, 2003). A pressão pela produtividade, o ritmo acelerado, a falta de autonomia no trabalho, a competitividade e a ameaça de desemprego são aspectos que influem o sofrimento psíquico (Sato \& Bernardo, 2005).

O processo de terceirização não é inédito e vem construindo espaços no mundo do trabalho, ao menos em nosso país, desde a década de 1970. Entretanto, se aprovado, ganhará mais força e apoio federal ao ser oficializado como prática político-econômica permitida, representando, dessa forma, um importante retrocesso das conquistas históricas de trabalhadores no Brasil.

Os achados deste estudo vão ao encontro das discussões trazidas sobre a crescente informalização do trabalho, especialmente no que concerne aos motoristas autônomos. A informalidade submete os trabalhos a contratos temporários, sem registro na carteira, sem estabilidade, inexistência do horário fixo de trabalho e as extensas jornadas de trabalho - sustentadas pelo uso das horas vagas dos trabalhadores, como meio de aumentar sua renda (Antunes, 2007, 2011; Chahad \& Cacciamali, 2005; Sauaya, 2003).

Estudo realizado com trabalhadores com contrato formal de trabalho e terceirizado em um serviço público de saúde mostrou que, em ambos os casos, os sintomas psíquicos apresentaram-se em forma de precariedade decorrentes da imposição da ideologia neoliberal. Precariedade objetiva no caso da trabalhadora terceirizada, decorrente do baixo salário e vínculo instável, e precariedade subjetiva no caso do trabalhador contratado formalmente, produzido pela sensação de mal-estar com relação ao trabalho (Bernardo, Verde, \& Pinzón, 2013).

Os objetivos previstos na Lei dos Caminhoneiros devem ser cumpridos por parte das autoridades governamentais, a fim de assegurar que o trabalho desses profissionais seja realizado em condições minimamente humanas, dignas, seguras. Entretanto, vive-se um momento histórico em que somos conduzidos por uma política econômica neoliberal, na qual trabalhadores encontram-se submetidos aos interesses unilaterais de 
empresas que buscam o lucro; na qual a saúde do trabalhador exerce um papel utilitário, importando saber apenas se está apto para exercer sua atividade e o quanto pode ser produtivo.

Este estudo revelou a importância de incluir os vínculos empregatícios ao compreender o trabalho de motoristas de caminhão, reforçando a necessidade de melhoria das condições de trabalho dos profissionais independentemente do seu vínculo. Isso porque, os curtos prazos de entrega, as más condições de rodovias e a falta de áreas de descanso adequadas, entre outros fatores, implicam em toda a categoria profissional, tanto do ponto de vista da saúde, quanto da qualidade de vida desses profissionais.

Sobre as limitações do estudo, apesar dos importantes achados acerca dos vínculos de trabalho e suas possíveis interferências na saúde de motoristas de caminhão, não é possível estender esses resultados para toda a população de caminheiros, uma vez que a pesquisa foi realizada em uma única empresa.

Tanto os motoristas contratados quanto os autônomos mencionaram a precariedade da infraestrutura das rodovias brasileiras e dos postos de parada. A informalidade no trabalho e os curtos prazos de entrega foram relacionados com o consumo de drogas, como anfetaminas, cocaína e crack.

Regulamentar a profissão e a jornada de trabalho representa um importante marco para a categoria profissional, entretanto, a informalidade e a precarização no trabalho, observadas no exercício desta profissão, podem comprometer e/ou agravar a saúde desses trabalhadores. A partir dos achados deste estudo, é importante refletir e discutir nas diferentes instâncias (políticas, econômicas e sociais) a crescente prática dos vínculos fragilizados, configurados pela terceirização, e o comprometimento com melhores e mais dignas condições de trabalho e saúde para os motoristas de caminhão e demais trabalhadores submetidos ao mesmo contexto.

\section{REFERÊNCIAS}

Agência Nacional de Transportes Terrestres. (2014). Registro nacional de transportadores rodoviários de cargas: Transportadores, frota de veículos. Recuperado de http://www.antt.gov.br/index.php/content/view/20270/Transportadores Frota_de_Veiculos.html

Antunes, R. (2007). Dimensão da precarização estrutural do trabalho. In G. Druck \& T. Franco (Orgs.), A perda da razão social do trabalho: Terceirização e precarização (pp. 13-22). São Paulo: Boitempo.

Antunes, R. (2011). Os modos de ser da informalidade: Rumo a uma nova era da precarização estrutural do trabalho? Serviço Social \& Sociedade, 107, 405-419. doi: 10.1590/0101-66282011000300002

Bardin, L. (2009). Análise de conteúdo. Lisboa, Portugal: Edições 70.

Barros, P. C. R., \& Mendes, A. M. B. (2003). Sofrimento psíquico no trabalho e estratégias defensivas dos operários terceirizados da construção civil. Psico-USF, 8(1), 63-70. doi: http://dx.doi.org/10.1590/S1413-82712003000100009

Bernardo, M. H., Verde, F. F., \& Pinzón, J. G. (2013). Vivências de trabalhadores com diferentes vínculos empregatícios em um laboratório público. Cadernos de Psicologia Social do Trabalho, 16(1), 119-133.

Botelho, L. J., Diesel, L. E., Adamczyk, J. F., \& Zeferino, M. T. (2011). Profissão motorista de caminhão: Uma visão (im) parcial. Saúde \& Transformação Social, 2(1), 108-113.

Cerqueira-Santos, E., \& Santana, M. (2014). Work satisfaction among truck drivers: A comparative study of self-employed and employees. Revista de Psicologia da UFC, 5(1), 109-120.

Chahad, J. P. Z, \& Cacciamali, M. C. (2005). As transformações estruturais no setor de transporte rodoviário e a reorganização no mercado de trabalho do motorista de caminhão no Brasil. Revista da Associação Brasileira de Estudos do Trabalho, 2(10), $1-26$.

Codarin, M. A. F., Moulatlet, E. M., Nehme, P., Ulhôa, M., \& Moreno, C. R. C. (2010). Associação entre prática de atividade física, escolaridade e perfil alimentar de motoristas de caminhão. Saúde e Sociedade, 19(2), 18-28. doi: 10.1590/S010412902010000200017

Ferreira, L. L. (1993). Análise coletiva do trabalho. Revista Brasileira de Saúde Ocupacional, 21(78), 7-19.

Ferreira, L. L. (2011). Psicodinâmica do trabalho e análise coletiva do trabalho. Travailler, 1(25), 97-107. doi: 10.3917/ trav.025.0109

Ferreira, L. L., Donatelli, S., \& Junior, F. A. R. (2003). Análise coletiva do trabalho de pescadores-mergulhadores de lagosta brasileiros. São Paulo: Fundacentro.

Ferreira, L. L., Gonzaga, M., C., Donatelli, S., \& Bussacos, M., A. (2008). Análise coletiva do trabalho dos cortadores de cana da região de Araraquara, São Paulo. São Paulo: Fundacentro. 
Ferreira, L. L., \& Iguti, A. M. (1996). O trabalho dos petroleiros: Perigoso, complexo, continuo e coletivo. São Paulo: Scritta.

Ferreira, L. L., Maciel, R. H., \& Paraguay, A. I. (1994). Isto é trabalho de gente? Vida, doença e trabalho no Brasil. In L. E. Rocha, R. M. Rigotto \& J. T. Buschinelli (Orgs.), A contribuição da ergonomia (pp. 215-231). Petrópolis: Vozes.

Ferreira, S., \& Alvarez, D. (2013). Organização do trabalho e comprometimento da saúde: Um estudo em caminhoneiros. Sistemas \& Gestão, 8(1), 58-66.

Kapron, R. A. (2012). Tempo, jornada e produtividade na história e trabalho dos caminhoneiros. Revista Latino-Americana de História, 1(3), 194-206.

Kalleberg, A. L. (2009). Precarious work, insecure workers: Employment relations in transition. American Sociological Review, 74(1), 1-22. doi: 10.1177/000312240907400101

Knauth, D. R., Leal, A. F., Pilecco, F. B., Seffner, F., \& Teixeira, A. M. F. B. (2012). Manter-se acordado: A vulnerabilidade dos caminhoneiros no Rio Grande do Sul. Revista de Saúde Pública, 46(5), 886-893. doi: http://dx.doi.org/10.1590/S003489102012000500016

Lei 12.619, de 30 de abril de 2012 (2012, 30 de abril). Dispõe sobre o exercício da profissão de motorista; altera a Consolidação das Leis do Trabalho - CLT, aprovada pelo Decreto-Lei no 5.452, de $1^{\circ}$ de maio de 1943, e as Leis nos 9.503 , de 23 de setembro de 1997, 10.233, de 5 de junho de 2001, 11.079, de 30 de dezembro de 2004, e 12.023, de 27 de agosto de 2009, para regular e disciplinar a jornada de trabalho e o tempo de direção do motorista profissional; e dá outras providências. Diário Oficial da União, Seção 1.

Lei 13.103, de 02 de março de 2015 (2015, 20 de julho). Dispõe sobre o exercício da profissão de motorista; altera a Consolidação das Leis do Trabalho - CLT, aprovada pelo Decreto-Lei n 5.452, de $1^{\circ}$ de maio de 1943 , e as Leis nºs 9.503 , de 23 de setembro de 1997 - Código de Trânsito Brasileiro, e 11.442, de 5 de janeiro de 2007 (empresas e transportadores autônomos de carga), para disciplinar a jornada de trabalho e o tempo de direção do motorista profissional; altera a Lei $n^{\circ}$ 7.408, de 25 de novembro de 1985; revoga dispositivos da Lei n 12.619, de 30 de abril de 2012; e dá outras providências. Diário Oficial da União, Seção 1.

Leyton, V., Sinagawa, D. M., Oliveira, K. C. B. G., Schmitz, W., Andreuccetti, G., De Martinis, B. S., ... Munoz D. R. (2012). Amphetamine, cocaine and cannabinoids use among truck drivers on the roads in the State of Sao Paulo, Brazil. Forensic Science International, 215, 25-27. doi: 10.1016/j.forsciint.2011.03.032.

Marques, A. C. P. R., Ribeiro, M., Laranjeira, R. R., \& Andrada, N. C. (2012). Abuso e dependência: Crack. Revista da Associação Médica Brasileira, 58(2), 141-153.

Martins, A. J. (2013). Sonolência e consumo de carboidratos entre motoristas de caminhão (Dissertação de mestrado). Recuperado de http://www.teses.usp.br/teses/disponiveis/6/6134/tde-21052013-163721/pt-br.php

Masson, V. A., \& Monteiro, M. I. (2010). Vulnerabilidade à doenças sexualmente transmissíveis/AIDS e uso de drogas psicoativas por caminhoneiros. Revista Brasileira de Enfermagem, 63(1), 79-83. doi: 10.1590/S0034-71672010000100013

Mendonça, E. M. C., Souza, D. M., \& Ferreira, L. L. (2009). O trabalho de professores na educação básica em Belém do Pará. São Paulo: Fundacentro.

Ministério dos Transportes. (2014). Pontos de parada. Questionário sobre pontos de parada nas estradas. Brasília: MT. Recuperado de http://www.transportes.gov.br/conteudo/2793-transporte-de-cargas-pontos-de-parada.html

Moreno, C. R. C, \& Rotenberg, L. (2009). Fatores determinantes da atividade dos motoristas de caminhão e repercussões à saúde: Um olhar a partir da análise coletiva do trabalho. Revista Brasileira de Saúde Ocupacional, 34(120), 128-138.

Nascimento, E. C., Nascimento, E., \& Silva, J. P. (2007). Uso de álcool e anfetaminas entre caminhoneiros de estrada. Revista de Saúde Pública, 41(2), 290-293. doi: 10.1590/S0034-89102007000200017

Oliveira, L. G. D., Souza, L. M. D. A. D., Barroso, L. P., Gouvêa, M. J. C., Almeida, C. V. D. D., Muñoz, D. R., \& Leyton, V. (2015). Occupational conditions and the risk of the use of amphetamines by truck drivers. Revista de Saúde Pública, 49, 1-9. doi: http://dx.doi.org/10.1590/S0034-8910.2015049005944

Penteado, R. Z., Gonçalves, C. G. O., Costa, D. D., \& Marques, J. M. (2008). Trabalho e saúde em motoristas de caminhão no interior de São Paulo. Saúde e Sociedade, 17(4), 1-16. doi: 10.1590/S0104-12902008000400005

Projeto de Lei n. 4330, de 26 de outubro de 2004 (2004, 24 de abril). Dispõe sobre o contrato de prestação de serviço a terceiros e as relações de trabalho dele decorrentes. Recuperado de http://www.camara.gov.br/proposicoesWeb/fichadetramitacao? dProposicao $=267841$

Pylkkönen, M., Sihvola, M., Hyvärinen, H. K., Puttonen, S., Hublin, C., \& Sallinen, M. (2015). Sleepiness, sleep, and use of sleepiness countermeasures in shift-working long-haul truck drivers. Accident Analysis \& Prevention, 80, 201-210. doi: 10.1016/j.aap.2015.03.031. 
Resolução 196/96. Dispõe sobre as diretrizes e normas regulamentadoras de pesquisas envolvendo seres humanos - Conselho Nacional de Saúde, Brasília, DF.

Rosa, I. (2006). Trajetórias de caminhoneiros nas estradas brasileiras. Cadernos de Pesquisa do Centro de Documentação e Pesquisa em História, 34, 84-93.

Sato, L., \& Bernardo, M. H. (2005). Saúde mental e trabalho: Os problemas que persistem. Ciência e Saúde Coletiva, 10(4), 869878. doi: 10.1590/S1413-81232005000400011

Sauaya, D. (2003). Salud mental y trabajo: Historia vital del trabajo um dispositivo psicossocial. Buenos Aires: Lugar.

Silva, L. G. (2011). O trabalho dos motoristas de caminhão: A relação entre vínculos empregatícios e acidentes de trabalho (Dissertação de mestrado). Recuperado de http://www.teses.usp.br/teses/disponiveis/6/6134/tde-24022011-111659/pt-br. php

Souza, J. C., Paiva, T., \& Reimão, R. (2005). Sleep habits, sleepiness and accidents among truck drivers. Arquivos de NeuroPsiquiatria, 63(4), 925-930. doi: 10.1590/S0004-282X2005000600004

Scheffer, M., Pasa, G. G., \& Almeida, R. M. M. (2010). Dependência de álcool, cocaína e crack e transtornos psiquiátricos. Psicologia: Teoria e Pesquisa, 26(3), 533-541.

Strauss, A., \& Corbin, J. (2008). Pesquisa qualitativa: Técnicas e procedimentos para o desenvolvimento de teoria fundamentada. (2a ed). Porto Alegre: Artmed.

Ulhôa, M. A., Marqueze, E. C., Lemos, L. C., Silva, L. G., Silva, A. A, Nehme, P., .... Moreno, C. R. C. (2010). Distúrbios psíquicos menores e condições de trabalho em motoristas de caminhão. Revista de Saúde Pública, 44(6), 1130-1136. doi:10.1590/ S0034-89102010000600019

Vilela, R. A. G., Iguti, A. M., \& Almeida, I. M. (2004). Culpa da vítima: Um modelo para perpetuar a impunidade nos acidentes de trabalho. Cadernos de Saúde Pública, 20(2), 570-579.

Williamson, A. (2007). Predictors of psychostimulant use by long-distance truck drivers. American Journal of Epidemiology, 166(11), 1320-1326. 